\title{
Antimicrobial-Resistance Pathogen Load and Public Health Risk of Drinking Water in South Gondar, Ethiopia
}

Chalachew Yenew ( $\sim$ chalachewyenew50@gmail.com )

Debre Tabor University https://orcid.org/0000-0003-1000-9220

Melese Kebede

Debre Tabor University

Melkamu Mulat

Teda Health Science College

\section{Research}

Keywords: Public Health risk, Antibiotic-resistance bacteria, Drinking water, Debre Tabor, Ethiopia

Posted Date: December 29th, 2020

DOI: https://doi.org/10.21203/rs.3.rs-135494/v1

License: (c) (i) This work is licensed under a Creative Commons Attribution 4.0 International License.

Read Full License 


\section{Abstract}

Objectives: This study aims to determine the contamination Antimicrobial-Resistance Pathogen load and Public Health Risk of Drinking Water in the case of Debre Tabor Town, Northwest Ethiopia.

Study design and period: A laboratory-based cross-sectional study design was employed from March to May 2020.

Methods: A total of 60 water samples were collected from the household tap and household drinking water storage container by following the standard microbial analysis method. Besides Sanitary survey was conducted for the municipal water supply system. Water samples were analyzed for differences in bacteriological parameters and drug-susceptibility patterns. Descriptive statistics, independent sample ttest, and multiple linear regression models were used to analyze the data.

Results: The drinking water was mostly contaminated with multiple antibiotics-resistance waterborne Escherichia coli 35\% (95\% Cl: 31.2\%, 46.9\%), Salmonella 22.7\% (95\% Cl: $23.2 \%, 28.7 \%)$, and Shigella 15\% (95\% Cl: $11.2 \%, 20.9 \%$ ). Approximately $52.78 \%$ and $36.11 \%$ of the tap and an equal $23.33 \%$ of the household storage container water samples were categorized under low and intermediate risks respectively, and the overall health risk index of the water samples showed that $45.83 \%, 41.67 \%$, and $12.5 \%$, of them, are categorized under low, intermediate and high-risk classes respectively.

Conclusion: The contamination of drinking water with antimicrobial-resistant waterborne bacteria in the community could indicate the likelihood of the occurrence of treatment failure and increased mortality. Hence, proper drinking water treatment and strict supervision are needed to prevent the contamination of the water and related consequences.

\section{Introduction}

Globally, antimicrobial resistance (AMR) pathogens posed the most significant public health and economic threats where ten million humans at risk, with 700,000 deaths per year and 100 trillion USD of economic loss by 2050 . Hence, these figures are assumed to increase significantly if preventive measures could not be done (1).

In Africa, most bacteria are 50 percent to 100 percent resistant to widely used antibiotics and results in more common treatment failure, increased morbidity, and mortality, chronic infection, increased infant and child death, and other worsening conditions (2). These threats may occur due to weak antibiotics regulatory capacity, circulation of substandard/counterfeit antibiotics, lack of antimicrobial surveillance strategies, weak laboratory capacity on AMR testing, lack of essential laboratory reagents for monitoring and evaluation, and limited quality assurance $(3,4)$.

The increasing occurrence of AMR pathogens and their threats was a concern of the high and low-income countries (5). 
The widespread emergence of AMR bacteria has become one of the most serious challenges in Ethiopia due to antibiotic- drug misuse, drug prescription without susceptibility test, self-medication, and a long stay in the hospital environment (6). Some experimental investigation and surveillance in Ethiopia, E. coli, Shigella, and Salmonella species showed a high level of resistance to frequently recommended antibiotics (7).

Assessment of qualities of urban water source and tap water distribution systems in Arba-Minch town showed that the distribution lines are the most contaminated with Waterborne Bacteria (WBB) such as Salmonella and Shigella (8).

On the other hand, a study conducted in North Gondar showed that $50 \%$ of water samples collected from water lines were contaminated with indicator WBB E.coli (9). Assessment of the level of AMR contamination and contamination source identification is highly relevant for policy intervention.

Therefore, this study aimed to assess the AMR Pathogen load and Public Health Risk of Drinking Water in the case of Debre Tabor Town, Northwest Ethiopia.

\section{Methods}

\subsection{Study design and period}

A laboratory-based cross-sectional study was carried out during a month from March-May 2020 at Debre Tabor town.

\subsection{Sample size determination and sampling technique}

A total of 60 water samples was taken by using equations derived from the World Health Organization( WHO) and United Nations International Children's Emergency Fund (UNICEF) (10).

\subsection{Water sample collection}

For bacteriological analysis, the samples were collected aseptically in an autoclaved bottle containing two drops of sodium thiosulfate $\left(10 \% \mathrm{Na}_{2} \mathrm{~S}_{2} \mathrm{O}_{3}\right)$ for complete neutralization of any residual chlorine if present and for preserving microbial contamination. Before taking a sample from the tap, the mouth of the tap was cleaned with a clean cloth to remove any dirt if present (11). Then, water taken from the tap was flushed for $5 \mathrm{~min}$ and; then sterilization of the mouth of the tap was done with a spirit of flame followed by cooling it with the water to run for 1-3 min at a medium flow (12). Then the sterilized bottle was opened and filled with water by leaving a small air space to make shaking before analysis easier. The collected water samples from each source were labeled and kept in a cold box containing ice freezer packs $\left(<4^{\circ} \mathrm{C}\right)$ and were transported to Felege Hiwot Referal Hospital.

\subsection{Sample processing techniques of WBB isolation and susceptibility testing}




\subsubsection{Sample preparation}

Every $10 \mathrm{ml}$ of water samples from different sources were aseptically homogenized into $90 \mathrm{ml}$ of sterile peptone water in a clean $250 \mathrm{ml}$ sterile flask, shaken and 1:10 dilution was subsequently made (13). For the samples collected from tap and household storage container sources, further dilution was made by diluting $1 \mathrm{ml}$ of each homogenized sample and $9 \mathrm{ml}$ of sterile $0.85 \%$ physiological saline solution $(\mathrm{NaCl})$ to make $10^{-5}$ dilution by using a vortex mixer. For water samples collected from the household tap and household storage container, the first homogenized sample was plated.

\subsubsection{WBB isolation and identification technique}

A $0.1 \mathrm{ml}$ of the prepared diluted sample was directly inoculated on differential and selective agar media after primary and secondary enrichment and incubated at $37^{\circ} \mathrm{C}$ for $18-24$ hours. After incubation, the isolates were determined by Lactose fermentation and precipitated bile salts with the appearance of dry, donut-shaped, with the surrounded dark pink area were used for presumptive identification of E. coli on the selective medium MacConkey agar and Thiosulfate and Ferric Citrate were used for observing hydrogen sulfide production with black centers for presumptive identification of Salmonella and Shigella on the selective medium SS agar as shown the Fig. 1.

\subsubsection{Multiple antibiotic-resistant profile testing}

Antimicrobial susceptibility testing was done for all the isolated WBB species. The slanted cultures were subcultured and purified. The pure colonies were inoculated into Nutrient Broth and incubated at $37^{\circ} \mathrm{C}$ for 18-24 hours. After incubation, the turbidity of the culture was adjusted to $0.5 \mathrm{McF}$ arland Standard to bring the cell density to approximately $107-108 \mathrm{cfu} / \mathrm{ml}$. The $0.5 \mathrm{McF}$ arland turbidity standard was prepared by mixing $0.05 \mathrm{ml} \mathrm{BaCl} 2$ (1\%) with $9.95 \mathrm{ml} \mathrm{H} 2 \mathrm{SO}$ (1\%). Muller-Hinton (MH) (Oxoid) plates were prepared and warmed to ambient temperature for plating. A sterile cotton swab was dipped into the standardized suspension. The culture was spread evenly over the entire surface of the Muller-Hinton agar plates by swabbing in three directions at $90^{\circ}$ of each spreading. The plates were allowed to dry before applying antimicrobial discs. The following standard and Oxoid drug discs were used: Vancomycin (VA) of $30 \mu \mathrm{g}$; Cotrimoxazole (SXT) of $25 \mu \mathrm{g}$; Ciproflaxicillin (Cip) of $5 \mu \mathrm{g}$; Doxycycline (DC) of $30 \mu \mathrm{g}$ and Amoxicillin (Amo) of $2 \mu \mathrm{g}$, that were commonly used antibiotics in Ethiopian healthcare facilities. multiple antibiotic-resistance indexes (MAR) were found out by the formula: MAR index of isolate $=$ No. of antibiotics to which an isolate is resistant/Total no. of antibiotics to which the isolate was exposed, based on the guidelines developed from Clinical and Laboratory Standards Institute of US (14).

\subsection{Health Risk analysis}

To assess the sanitary condition of the water samples and to analyze the risk to health matrix, the World Health Organization (WHO) standards defined and recommended to determine the degree of contamination were used (15). Besides, Data on sanitary inspection of water sources were collected using the standard format described by WHO and UNICEF (16). 
Observation checklist containing 10 item observation checklists (sanitary inspection form). These forms consist of a set of questions with "yes" or "no" answers to help in finding the most important factors that contribute to the contamination of water. To each item, a risk factor was assigned with a score of 1 for "yes" while anyone that does not constitutes a risk factor was assigned a score of 0 for "no". A combination of the scores for each item gave the sanitary risk scores which were grouped into four categories: $0-2,3-5,6-8$, and 9-10 for low, moderate, high, and very high risk of contamination respectively.

\subsection{Quality control}

To ensure reliability, confidentiality, and validity during field and experiment, different strategies were employed. Triplicate and duplicate samples were collected for physicochemical and bacteriological analysis of both municipal water supply and hand-dug well water and the average of each result were taken for the analysis. Observational checklists were also used to make sure the handling of water sources. Information on each sampling site and identification of the sampling locations were done by GPS. To assure and control the quality of data during sample analysis, series of events like cleaning of laboratory glassware and calibration of field equipment were performed just before and just after field measurements to ensure the validity and accuracy of acquired data. Bacteriological quality of drinking water was processed according to standard operating procedures and laboratory safety rule was followed. Sample collecting bottles were serialized before sample collection. To check the sterility of prepared media, $5 \%$ of the prepared batch of media was incubated overnight and checked for microbial growth in the media. Field blank, positive control negative control and also internal quality control was used to assure the quality of species identification and the antimicrobial susceptibility test.

\subsection{Data analysis}

The data were coded and entered using Epi info 7 and exported to STATA version 16.then the Mean prevalence, variability, and linear regression were executed by using STATA statistical software version 16. The variances between groups were handled by analysis of variance (ANOVA). A multiple linear regression model was conducted to determine the relationship between AMR WBB of drinking water with associated factors.

\section{Results}

\subsection{Household hygienic practices for handling the drinking water}

The hygienic practice, observation of household tap water, and household storage containers concerning the sanitary inspection checklists are presented in Table 1. Accordingly, in the study area, most (63.9\%) of the respondents treat their water, which is fetched from the tap before consumption. Out of the total respondents treat their drinking water, most of them (55.88\%) uses ceramic water filter while the remaining $23.53 \%$ and $20.58 \%$ add chorine and boiling method, respectively. From the total tap waters 
assessed about $30.56 \%$ of the area around the tap was a bad hygienic environment. Besides, $36.11 \%$ of the drinking water storage containers had poor hygiene (Table 1).

Table 1

The hygienic status of household tap and storage containers found in Debre Tabor town, Ethiopia, March 2020.

\begin{tabular}{|c|c|c|c|}
\hline S.NO & Items & Alternative & $\begin{array}{l}\text { Respondent } \\
(\%)\end{array}$ \\
\hline \multirow[t]{2}{*}{1.} & \multirow[t]{2}{*}{ Do you use anything to make drinking water safer? } & $\cdot$ Yes & 63.9 \\
\hline & & $\cdot$ NO & 36.1 \\
\hline \multirow[t]{3}{*}{2.} & \multirow[t]{3}{*}{ Methods used to make drinking water safer? } & - Boiling & 20.58 \\
\hline & & $\begin{array}{l}\text { - Adding } \\
\text { chlorine }\end{array}$ & 23.53 \\
\hline & & $\begin{array}{l}\text { - Water } \\
\text { fillter }\end{array}$ & 55.88 \\
\hline \multirow[t]{2}{*}{3.} & \multirow{2}{*}{$\begin{array}{l}\text { Are there any flies, dust and other contaminants around the } \\
\text { area of the tap? }\end{array}$} & $\cdot$ Yes & 30.56 \\
\hline & & $\cdot \mathrm{NO}$ & 69.44 \\
\hline \multirow[t]{2}{*}{4.} & \multirow{2}{*}{$\begin{array}{l}\text { Are there any flies, dust and other contaminants around the } \\
\text { area/on the storage container? }\end{array}$} & $\cdot$ Yes & 36.11 \\
\hline & & - NO & 63.89 \\
\hline
\end{tabular}

\subsection{WBB analysis of drinking water of Debre Tabor Town}

To determine the WBB of water samples collected from the household tap and household storage container, the presence and concentration of Salmonella, Shigella, Total coliform, and E. coli was assessed. The result of the microbiological quality of water samples from the household taps and a storage container as compared with national/WHO/EPA guidelines. The result showed that about $27 \%$ (95\% Cl: $21.10-33.48)$ and $50 \%$ (95\% Cl: 44.15-69.14) of the water samples collected from the household tap and storage container were positive for the Total coliform bacterial contamination respectively. The adjusted mean \pm SD of E.coli counts for water samples collected from the household tap and household container were $1.70 \pm 3.45$ and $6.32 \pm 7.61 \mathrm{CFU} / 100 \mathrm{ml}$ respectively.

In this study, about $23 \%(95 \% \mathrm{Cl}: 10-100 \mathrm{CFU} / 100 \mathrm{ml})$ and $3 \%$ (95\% Cl: $1-10 \mathrm{CFU} / 100 \mathrm{ml})$ water samples were collected from taps and household containers that had Shigella counts respectively. Besides, about 33.33\% (95\% Cl: 10-100 CFU/100 ml) and 23\% (95\% Cl: 10-100 CFU/100 ml) tap and storage container water samples had Salmonella counts respectively (Table 2). 
Table 2

Summary of WBB counts (\% or CFU/100 ml) of the water samples collected from the tap and household storage containers of Debre Tabor town, Ethiopia, March 2020.

\begin{tabular}{|c|c|c|c|c|}
\hline WBB & $\mathbf{N}$ & Frequency & Adjusted Mean \pm SD & WHO, 2004 standard \\
\hline \multicolumn{5}{|c|}{ Water is taken from the tap } \\
\hline TC & 30 & $8(27 \%)$ & $11.19 \pm 11.45$ & \\
\hline Shigella & 30 & $7(23 \%)$ & $1.72 \pm 3.45$ & $0 \mathrm{cfu} / 100 \mathrm{ml}(\mathrm{A})$ \\
\hline Salmonella & 30 & $10(33 \%)$ & $2.87 \log \mathrm{CFU} / \mathrm{ml} \pm 2.63 \log \mathrm{CFU} / \mathrm{ml}$ & $500 \mathrm{cfu} / \mathrm{ml}(\mathrm{P})$ \\
\hline E.coli & 30 & $14(46 \%)$ & - & $0 \mathrm{cfu} / 100 \mathrm{ml}(\mathrm{A})$ \\
\hline \multicolumn{5}{|c|}{ Water is taken from household storage container } \\
\hline TC & 30 & $15(50 \%)$ & $47.15 \pm 27.0$ & \\
\hline Shigella & 30 & $2(3 \%)$ & $2.32 \pm 1.61$ & $0 \mathrm{cfu} / 100 \mathrm{ml}(\mathrm{A})$ \\
\hline Salmonella & 30 & $7(23 \%)$ & $3.02 \log \mathrm{CFU} / \mathrm{ml} \pm 2.71 \mathrm{log} \mathrm{CFU} / \mathrm{ml}$ & $500 \mathrm{cfu} / \mathrm{ml}(\mathrm{P})$ \\
\hline E.coli & 30 & $10(30 \%)$ & & $0 \mathrm{cfu} / 100 \mathrm{ml}(\mathrm{A})$ \\
\hline
\end{tabular}

The three major public health concern and common WBB isolate obtained from different combinations of enrichment, selective and differential media were tested for an array of five different antibiotics. Most of the isolated WBB are resistant to SXT $(25 \mu \mathrm{g})$; Amo $(2 \mu \mathrm{g})$; VA $(30 \mu \mathrm{g})$, none was resistant to ciprofloxacin. Most isolated WBB showed MDR (Table 3). 
Table 3

Mixed effect model analysis of the MDR levels of WBB of the water samples collected from the tap and household storage containers of Debre Tabor town, Ethiopia, March 2020.

\begin{tabular}{|c|c|c|c|c|c|c|}
\hline \multirow[t]{2}{*}{ WBB } & \multicolumn{2}{|l|}{ Resistance } & \multicolumn{2}{|l|}{ Sensitive } & \multirow{2}{*}{$\begin{array}{l}\text { Mean } \\
\text { MDR }\end{array}$} & \multirow{2}{*}{$\begin{array}{l}\text { MAR } \\
\text { Index }\end{array}$} \\
\hline & Antibiotics & MIZ & Antibiotics & MIZ & & \\
\hline \multirow[t]{4}{*}{ E.coli } & \multirow{2}{*}{$\begin{array}{l}\text { SXT } \\
(25 \mu \mathrm{g})\end{array}$} & 8.07 mm & Cip $(5 \mu g)$ & $25.50 \mathrm{~mm}$ & \multirow[t]{4}{*}{$94.43 \%$} & \multirow[t]{4}{*}{0.6} \\
\hline & & \multirow[t]{3}{*}{$(95 \% \mathrm{Cl}: 6.63,9.8)$} & \multirow[t]{3}{*}{$\mathrm{DC}(30 \mu \mathrm{g})$} & \multirow{3}{*}{$\begin{array}{l}\text { (95\%Cl: } 22, \\
29.45)\end{array}$} & & \\
\hline & $\begin{array}{l}\text { Amo } \\
(2 \mu \mathrm{g})\end{array}$ & & & & & \\
\hline & VA $(30 \mu g)$ & & & & & \\
\hline \multirow[t]{4}{*}{ Salmonella } & \multirow{2}{*}{$\begin{array}{l}\text { SXT } \\
(25 \mu \mathrm{g})\end{array}$} & 7.77 mm & \multirow{4}{*}{$\begin{array}{l}\text { Cip }(5 \mu g) ; \text { DC } \\
(30 \mu g)\end{array}$} & $27.50 \mathrm{~mm}$ & \multirow[t]{4}{*}{$85 \%$} & \multirow[t]{4}{*}{0.6} \\
\hline & & \multirow{3}{*}{$\begin{array}{l}\text { (95\%Cl: } 5.90 \\
9.43)\end{array}$} & & \multirow{3}{*}{$\begin{array}{l}\text { (95\%Cl: } \\
23.25,30.45)\end{array}$} & & \\
\hline & $\begin{array}{l}\text { Amo } \\
(2 \mu g)\end{array}$ & & & & & \\
\hline & VA $(30 \mu g)$ & & & & & \\
\hline \multirow[t]{5}{*}{ Shigella } & SXT & \multirow{5}{*}{$\begin{array}{l}8.75 \mathrm{~mm}(95 \% \mathrm{Cl}: \\
6.98,9.90)\end{array}$} & \multirow[t]{5}{*}{ Cip $(5 \mu g)$} & \multirow{5}{*}{$\begin{array}{l}19 \mathrm{~mm} \\
(95 \% \mathrm{Cl}: 16.5 \text {, } \\
23.2)\end{array}$} & \multirow[t]{5}{*}{$89.58 \%$} & \multirow[t]{5}{*}{0.8} \\
\hline & & & & & & \\
\hline & $\begin{array}{l}\text { Amo } \\
(2 \mu \mathrm{g})\end{array}$ & & & & & \\
\hline & $\begin{array}{l}\text { VA } \\
(30 \mu \mathrm{g})\end{array}$ & & & & & \\
\hline & $\begin{array}{l}\text { DC } \\
(30 \mu \mathrm{g})\end{array}$ & & & & & \\
\hline
\end{tabular}

\subsection{Health Risks of Drinking Water of Debre Tabor Town}

In this study, analysis of household container water samples revealed that half $10(50 \%)$, of the household's container water samples, was free from Fecal contamination (FC) (low risk of contamination) (Table 4). The Chi-square test analysis revealed that the sanitary inspection (SI) level of risk score had a strong association with the FC quality of both tap and household storage container water samples $(p<0.05)$. However, the SI level of risk score had no significant association with the TC quality of both tap and household storage container water samples $(p>0.05)$. 
Table 4

Risk determination of WBB in case of drinking water samples of Debre Tabor town, Ethiopia, 2020.

\begin{tabular}{|c|c|c|c|c|c|c|c|c|c|c|c|}
\hline \multirow[t]{2}{*}{ Water sample } & \multirow[t]{2}{*}{ SI } & \multicolumn{5}{|c|}{ Total coliform } & \multicolumn{5}{|c|}{ Fecal coliform } \\
\hline & & 0 & $\begin{array}{l}1- \\
10\end{array}$ & $\begin{array}{l}10- \\
100\end{array}$ & $\begin{array}{l}100- \\
1000\end{array}$ & $\begin{array}{l}> \\
1000\end{array}$ & 0 & $\begin{array}{l}1- \\
10\end{array}$ & $\begin{array}{l}10- \\
100\end{array}$ & $\begin{array}{l}100- \\
1000\end{array}$ & $\overrightarrow{1000}$ \\
\hline \multirow[t]{4}{*}{ Tap } & $\begin{array}{l}1- \\
2-\end{array}$ & 5 & 4 & 2 & 0 & 0 & 19 & 1 & 1 & 0 & 0 \\
\hline & $\begin{array}{l}3- \\
5\end{array}$ & 3 & 8 & 11 & 0 & 0 & 7 & 5 & 0 & 0 & 0 \\
\hline & $\begin{array}{l}6- \\
8\end{array}$ & 0 & 0 & 3 & 0 & 0 & 0 & 3 & 0 & 0 & 0 \\
\hline & $\begin{array}{l}9- \\
10\end{array}$ & 0 & 0 & 0 & 0 & 0 & 0 & 0 & 0 & 0 & 0 \\
\hline \multirow[t]{4}{*}{$\begin{array}{l}\text { Household storage } \\
\text { Container }\end{array}$} & $\begin{array}{l}1- \\
2-\end{array}$ & 0 & 4 & 18 & 0 & 0 & 12 & 3 & 1 & 0 & 0 \\
\hline & $\begin{array}{l}3- \\
5\end{array}$ & 0 & 0 & 10 & 3 & 0 & 6 & 3 & 10 & 0 & 0 \\
\hline & $\begin{array}{l}6- \\
8\end{array}$ & 0 & 0 & 1 & 0 & 0 & 0 & 0 & 1 & 0 & 0 \\
\hline & $\begin{array}{l}9- \\
10\end{array}$ & 0 & 0 & 0 & 0 & 0 & 0 & 0 & 0 & 0 & 0 \\
\hline
\end{tabular}

According to both criteria, approximately $52.78 \%$ and $36.11 \%$ of the tap and an equal $23.33 \%$ of the household storage container water samples were categorized under low and intermediate risks respectively, and the overall health risk index of the water samples showed that $45.83 \%, 41.67 \%$, and $12.5 \%$, of them, are categorized under low, intermediate and high-risk classes respectively.

\subsection{Associated factors of AMR WBB on drinking water}

Correlation analysis of the WBB, their growth parameters, and the level of sanitary risk is shown in Table 5. Most of the bacteriological parameters showed a significant positive correlation with the SI level of risk and a significant negative correlation with residual chlorine concentration. From all the bacteriological parameters assessed, TC in the drinking water storage container showed a strong positive correlation $(r=0.856, p<0.01)$ with the $S \mathrm{I}$ and a strong negative correlation with residual chlorine concentration $(r=-0.622, p<0.01)$ (Table 5). 
Table 5

Correlation analysis output of WBB growth parameters, sanitary inspection risk score, and drug use characteristics (CHXS) with AMR WBB load for each water sample in Debre Tabor town, Ethiopia, 2020.

\section{Growth parameters AMR WBB}

\begin{tabular}{|c|c|c|c|c|c|c|}
\hline & \multicolumn{3}{|c|}{ On Tap water } & \multicolumn{3}{|c|}{ On Household storage container water } \\
\hline & E.coli & Salmonella & TC & E.coli & Salmonella & TC \\
\hline $\mathrm{Ph}$ & -0.106 & -0.144 & -0.097 & -0.091 & -0.046 & -0.023 \\
\hline Conductivity & -0.289 & -0.209 & -0.157 & -0.037 & 0.089 & -0.061 \\
\hline Turbidity & 0.164 & 0.084 & 0.207 & 0.001 & 0.008 & 0.116 \\
\hline Residual chlorine & $-0.674^{\star \star}$ & $-0.713^{\star \star}$ & $-0.633^{\star \star}$ & $-0.787^{\star \star}$ & $-0.620 \star \star$ & $-0.622^{\star \star}$ \\
\hline Drug use $\mathrm{CHXS}$ & 0.004 & 0.084 & 0.007 & 0.001 & 0.008 & 0.016 \\
\hline Level of risk & $0.711^{\star *}$ & $0.601 * *$ & $0.493 * \star$ & $0.741 * *$ & $0.562^{\star *}$ & $0.856 * *$ \\
\hline
\end{tabular}

\section{Discussion}

WBB of drinking water determination is a good representative of public health risk since it can be a medium for the transmission of pathogenic disease, particularly deriving from fecal contamination.

A similar study conducted in Nekemte town has shown that $37 \%$ of the drinking water were contaminated with FC which is above the present study (17). But, the present study E.coli finding is higher than the studies conducted in Addis Ababa City (2.4\%) (18) and Dharan, Nepal town (21.1\%) (11). This difference may be due to the difference in the safety and quality control of water through the evaluation of water sources and manage contamination of water supply. Also, it may associate with the frequent pipe breakage, leakage, and the passing of pipelines through the ditches and drainage systems.

The E.coli load was higher than the study conducted in Kolladiba town of Ethiopia (32.5\%) (19) and lower than Babati town, Tanzania (86\%) of drinking water samples were contaminated with E.coli (20). The difference might be treatment of the drinking water and variation in climatic conditions.

According to Temesgen \& Hameed, (2015) drinking water can be contaminated with AMR WBB due to improper treatment of water and the existence of poor sanitation (22). Assessment of qualities of urban water source and tap water distribution systems in Arba-Minch town revealed that the distribution lines are the most contaminated with AMR WBB such as Salmonella and Shigella (8).

The relationship between sanitary inspection scores and the bacteriological risk category is used to identify the level of risk of contamination due to AMR WBB. A study conducted by Tsega et al. (2013), showed that the total sanitary risk score has a significant relationship with the level of fecal 
contamination (23). And also A similar study conducted in Bahir Dar town showed that $45.7 \%$ and $11.4 \%$ of drinking water samples had low and very high-risk scores respectively (24). Accordingly, the reason for the difference in risk score between the present study and the study conducted by Milkiyas et al. (2011) and Tsega et al. (2013) might be the hygiene and sanitation condition of water storage container, awareness of the community towards water storage container and dose of residual chlorine.

\section{Conclusions}

The drinking water was mostly contaminated with AMR WBB Escherichia coli 35\% (95\% Cl: 31.2\%, 46.9\%), Salmonella $22.7 \%$ (95\% Cl: 23.2\%, 28.7\%), and Shigella 15\% (95\% Cl: 11.2\%, 20.9\%). Approximately $52.78 \%$ and $36.11 \%$ of the tap and an equal $23.33 \%$ of the household storage container water samples were categorized under low and intermediate risks respectively, and the overall health risk index of the water samples showed that $45.83 \%, 41.67 \%$, and $12.5 \%$, of them, are categorized under low, intermediate and high-risk classes respectively.

The finding of this study has shown possible health hazards related to the consumption of drinking water. Identification of these hazards would help health officials to pay attention to safety and quality issues regarding drinking water. It will also contribute to awareness of consumers and water sector officials about safety and quality issues related to consumption of drinking water. It may encourage water sector officials to follow proper water treatment procedures during distribution up to consumption. The finding suggests the importance of water quality training for human working in water sectors, implementation of proper water treatment and strict follow up of the implementation of acceptable hygienic practices might improve water quality. Besides minimizing irrational drug use could also help to reduce AMR in water and the environment.

\section{Declarations}

\subsection{Ethics Approval:}

Ethical clearance was obtained from the Institutional Review Board of the Jimma University and an official letter was submitted to the concerned bodies. The concerned bodies were informed to get the assurance of the study and confidentiality was maintained at all levels of the study. Informed consent was obtained from all participants and the Institutional Review Board of the Jimma University approved it with Ethical approval of Research protocol letter with its reference number IRB00010/2020.

\subsection{Consent to Publish:}

Not applicable.

\subsection{Availability of data and materials:}

All data generated and analyzed during this study are included in the manuscript. 


\subsection{Competing interests:}

The authors declare that they have no competing interests.

\subsection{Authors' contribution:}

MK has been actively involved during the conception of research issues, MM is involved in the development of research proposals, and $\mathrm{CY}$ has been involved in the writing of various parts of the research report and prepares the final manuscript. All authors read and approved the final manuscript.

\subsection{Acknowledgments:}

Firstly, we would like to give our heartfelt thanks to the almighty God for giving us the knowledge, and all the support we needed to do this study.

We also would like to acknowledge the Jimma University, Institute Health Sciences, Public Health Faculty, and Department of Environmental Health Sciences and Technology for the arrangement and administrative support of our study.

Lastly, but not least, We would like to acknowledge the Debre Tabor University for giving the necessary information and some laboratory reagents for the study and Felege Hiwot comprehensive specialized Hospital for doing the laboratory analysis of the study.

\section{Abbreviations}

WBB: Waterborne Bacteria; Cls: Confidence Intervals; WHO: World Health Organization; US: United State; EPA: Environmental Protection Agency; E. coli: Escherichia coli; ARR: Antibiotic Resistance Rate; MIZ: Mean Inhibition Zone: MDR: Multidrug Resistance: $\mathrm{mg} / \mathrm{l}$ : milligram per liter, $\mathrm{pH}$ : negative logarithmic concentration of hydrogen, SD: Standard Deviation: SI: Sanitary Inspection, TC: Total Coliform; UNICEF: United Nations Children's Fund

\section{References}

1. Viens. Is Antimicrobial Resistance a Slowly Emerging Disaster? AMR: Challenge, Threat. Public Health Ethics. 2015;8(3):255-65.

2. Ampaire et al. AMR in East Africa. Afr J Lab Med. 2016;5(1).

3. Ndihokubwayo et al. Antimicrobial resistance in the African Region: Issues, challenges, and actions proposed. WHO, Reg Off Africa. 2013;(16).

4. Founou et al. Antibiotic Resistance in Food Animals in Africa. Microb drug-resistant. 2018;24(5).

5. Aastha et al. Global Contributors to Antibiotic Resistance. JGlobal Infect Dis. 2019;11(3).

6. Tamiru et al. patterns of researches done on antimicrobial resistance in Ethiopia. Indo Am J Pharm Res. 2017;7(09). 
7. Moges et al. The growing challenges of antibacterial drug resistance in Ethiopia. Elsevier $\mathrm{J}$ Antimicrob Resist. 2014;2(3):148-54.

8. Ameya G, Tsalla T, Getu F, Getu E. Antimicrobial susceptibility pattern, and associated factors of Salmonella and Shigella infections among under five children in Arba Minch, South Ethiopia. Ann Clin Microbiol Antimicrob [Internet]. 2018;17(1):1-8. Available from: https://doi.org/10.1186/s12941018-0253-1

9. Admassu M, Wubshet M, Gelaw B. A survey of bacteriological quality of drinking water in North Gondar. Ethiop J Heal Dev. 2005;18(2).

10. WHO and UNICEF. D inking Water. 2012;

11. Pant ND, Poudyal N, Bhattacharya SK. Bacteriological quality of bottled drinking water versus municipal tap water in Dharan municipality, Nepal. J Heal Popul Nutr. 2016;35(17):1-6.

12. Pant ND, Poudyal N, Bhattacharya SK. Bacteriological Quality of Drinking Water Sources and Reservoirs Supplying Dharan Municipality of Nepal. Ann Clin Chem Lab Med. 2016;2(1):19-23.

13. Bhuyan MS, Bakar MA, Sharif ASM, Hasan M, Islam MS. Water Quality Assessment Using Water Quality Indicators and Multivariate Analyses of the Old Brahmaputra River. Pollution. 2018;4(3):48193.

14. Clinical and Laboratory Standards Institute. Performance Standards for Antimicrobial Susceptibility Testing Supplement M100S. 26th ed. 2016. 1-256 p.

15. WHO. Guidelines for Drinking-water Quality- 4th edn. Printed in Malta by Gutenberg. 2011.

16. WHO and UNICEF. Rapid Assessmen t of Drinking-water Quality: A Handbook for Implementation. 2012.

17. Gonfa D, Fassil A, Mulissa J. Assessment of Bacteriological and Physicochemical Quality of Drinking Water from Source to Household Tap Connection in Nekemte, Oromia, Ethiopia. J Environ Public Health. 2019;2019:1-7.

18. Amsalu MW, Kemal J, Gebru MW, Kassu DT. Quality and safety of municipal drinking water in Addis Ababa City, Ethiopia. Environ Health Prev Med. 2020;25(9):1-6.

19. Sharma HR, Worku W, Hassen M, Tadesse Y, Zewdu M, Kibret D, et al. Water handling practices and level of contamination between source and point-of-use in Kolladiba Town, Ethiopia. Environ We Int $\mathrm{J}$ Sci Technol [Internet]. 2013;8(January):25-35. Available from: files/53/Sharma et al. - 2013 - Water handling practices and level of contaminatio.pdf\%0Afiles/52/Sharma et al. - 2013 - Water handling practices and level of contaminatio.pdf

20. Tesha I. Determination of source-to-consumption waterhandling chains and their implications on water quality and human health in Babati town, Manyara, Tanzania. 2018; Available from: http://dspace.nm-aist.ac.tz/handle/123456789/240

21. Temesgen E, Hameed S. Assessment of physico-chemical and bacteriological quality of drinking water at sources and household in Adama Town, Oromia Regional State, Ethiopia. African J Environ Sci Technol. 2015;9(5):413-9. 
22. Temesgen E, Hameed S. Assessment of physico-chemical and bacteriological quality of drinking water at sources and household in Adama Town, Oromia Regional State, Ethiopia. African J Environ Sci Technol. 2015;9(5):413-9.

23. Pindi PK, Yadav PR, Kodaparthi A. Bacteriological and physico-chemical quality of main drinking water sources. Polish J Environ Stud. 2013;22(3):825-30.

24. Milkiyas Tabor, Mulugeta Kibret BA. Original Article Bacteriological and Physicochemical Quality of Drinking Water and Hygiene- Sanitation Practices of the Consumers in. :19-26.

\section{Figures}
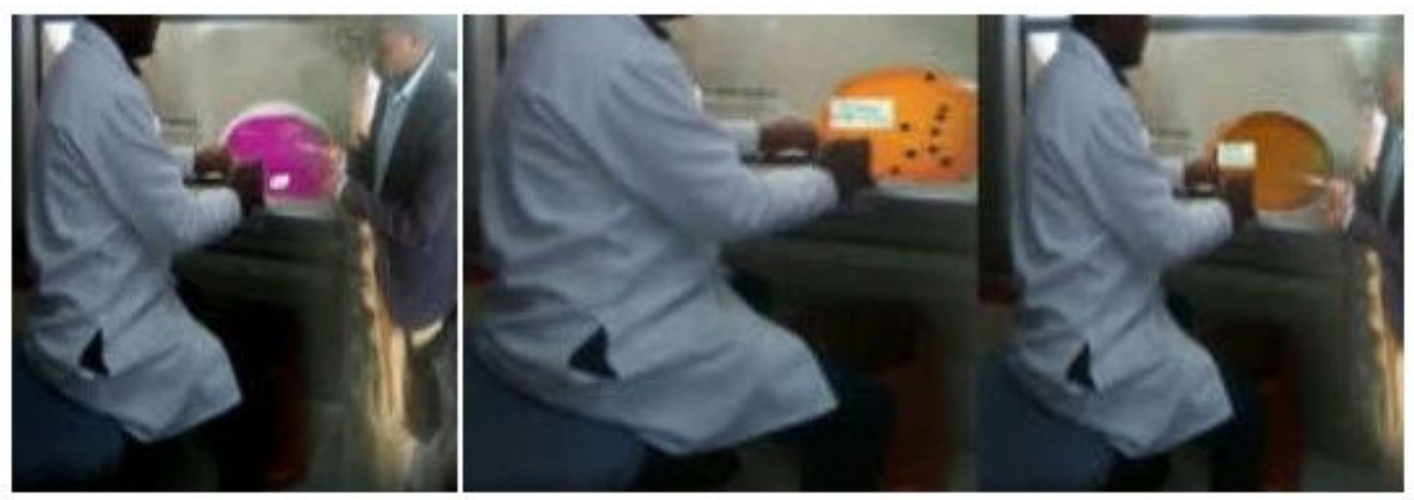

\section{Figure 1}

Identified colonies of the WBB in drinking water of South Gondar, Ethiopia, March 2020. 